\title{
Biomarkers for susceptibility to infection and disease severity in human malaria
}

\author{
Bruno Bezerril Andrade', Manoel Barral-Netto ${ }^{2,3,4 /+}$ \\ ${ }^{1}$ Laboratory of Parasitic Diseases, National Institute of Allergy and Infectious Diseases, National Institutes of Health, Bethesda, MD, USA \\ ${ }^{2}$ Faculdade de Medicina, Universidade Federal da Bahia, Salvador, BA, Brasil ${ }^{3}$ Centro de Pesquisas Gonçalo Moniz-Fiocruz, Salvador, BA, Brasil \\ ${ }^{4}$ Instituto Nacional de Ciência e Tecnologia de Investigação em Imunologia, Salvador, BA, Brasil
}

Malaria remains a major infectious disease that affects millions of people. Once infected with Plasmodium parasites, a host can develop a broad range of clinical presentations, which result from complex interactions between factors derived from the host, the parasite and the environment. Intense research has focused on the identification of reliable predictors for exposure, susceptibility to infection and the development of severe complications during malaria. Although most promising markers are based on the current understanding of malaria immunopathogenesis, some are also focused more broadly on mechanisms of tissue damage and inflammation. Taken together, these markers can help optimise therapeutic strategies and reduce disease burden. Here, we review the recent advances in the identification of malarial biomarkers, focusing on those related to parasite exposure and disease susceptibility. We also discuss priorities for research in biomarkers for severe malaria.

Key words: malaria - Plasmodium - biomarker - inflammation

Despite continuous efforts by both governmental and private initiatives to eliminate malaria, Plasmodium infections still result in millions of deaths annually worldwide. Approximately two thirds of the world's population lives in areas at risk for malaria (Guerra et al. 2008, Hay et al. 2009). Among the five Plasmodium species that can cause human disease, Plasmodium falciparum and Plasmodium vivax represent the majority of infections. In fact, globally, $P$. falciparum has been responsible for the majority of malaria-associated mortality (Guerra et al. 2008); however, vivax malaria, previously considered a benign disease, has now clearly emerged as a potentially lethal condition (Anstey et al. 2009), particularly in non-African endemic regions. $P$. vivax is also more widely distributed than P. falciparum and has potential to cause morbidity and mortality amongst the 2.85 billion people living at risk of infection (Guerra et al. 2010). In Brazil, P. vivax accounts for up to $80 \%$ of the malaria cases (Oliveira-Ferreira et al. 2010). Techniques for adequate malaria control are based on the development of sensitive diagnostic tools, effective treatments and the successful implementation of preventive strategies using bed nets and insecticides. Despite more than 40 years of tremendous investments, no reliable vaccine is available to prevent malaria, in part because Plasmodium parasites have evolved a number of evasion mechanisms that subvert host immune responses. Understanding the nuances of malaria immunopathogenesis is fundamental to the development of innovative approaches to reduce disease burden.

Financial support: FINEP (010409605)/FNDCT-CT Amazônia

$\mathrm{MBN}$ is a senior investigator from CNPq.

+Corresponding author: mbarral@bahia.fiocruz.br

Received 9 February 2011

Accepted 25 April 2011
Once infected with Plasmodium, a human host generally presents with one of three major clinical outcomes: asymptomatic infection, mild disease or severe disease. These diverse clinical presentations are determined by complex interactions between the host, the parasite and environmental factors (Fig. 1). Parasite determinants include the different pathogenic potential of the various Plasmodium species. For example, P. falciparum is well known to cause severe infections more frequently than other Plasmodium species because $P$. falciparum exhibits a number of unique characteristics that favour increased disease severity, including high multiplication rates in both erythrocytes and reticulocytes, strong cytoadherence to infected erythrocytes [reviewed in Schofield (2007)] and toxin-induced activation of inflammatory responses [reviewed in Clark and Cowden (1999)]. Interestingly, cases of severe malaria caused by $P$. vivax (Andrade et al. 2010c) or uncommon Plasmodium species (Cox-Singh et al. 2010) display patterns of inflammation and immunopathology similar to those seen in severe falciparum malaria cases. These findings suggest that different Plasmodium species can trigger strikingly similar host responses that can result in severe disease. A number of host factors have already been described as important determinants of clinical outcomes in malaria cases, including age and gender, ethnicity, concomitant chronic conditions, co-infections and diverse genetic polymorphisms. Environmental factors include deforestation, health care system infrastructure and access to effective antimalarial treatment, vector exposure and sociocultural factors. Within the clinical spectrum of Plasmodium infections, we consider the two opposite poles that remain to be fully understood of utmost importance: asymptomatic malaria, which is directly associated with clinical immunity to infection and severe malaria, which underlies key processes in susceptibility to infection. 


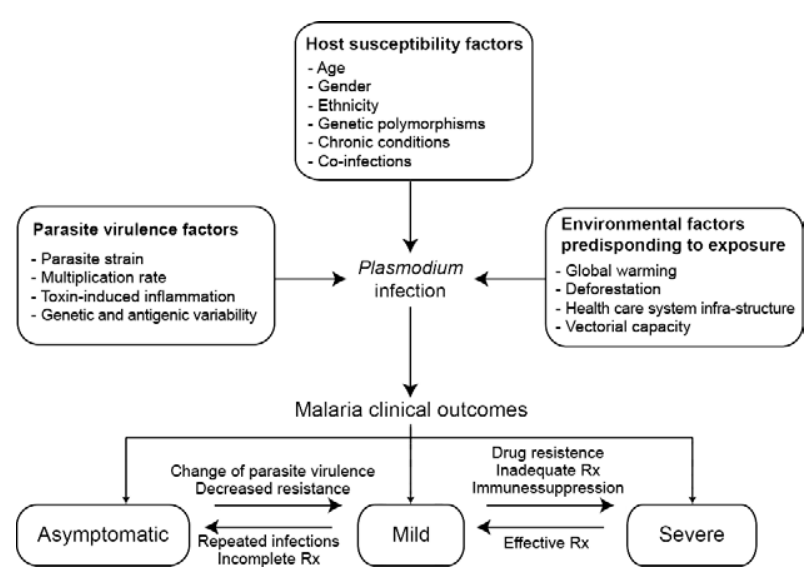

Fig. 1: determinants of human malaria. The susceptibility to Plasmodium infection results from a complex combination of factors from the host, parasite and environment. The degree of susceptibility can result in diverse clinical outcomes, ranging from asymptomatic infections to severe and lethal disease. Furthermore, an infected individual can progress from one clinical presentation to another depending on additional factors such as therapeutic efficacy, parasite drug resistance, changes in parasite virulence and changes in host immunocompetence. A major challenge is to identify reliable predictors of undesirable outcomes and reduce disease burden. Rx: treatment.

Several epidemiological studies have shown that cases of asymptomatic malaria are highly prevalent in many endemic regions (Cucunubá et al. 2008, Baliraine et al. 2009, Marangi et al. 2009, Steenkeste et al. 2010). Individuals with asymptomatic Plasmodium infection can exhibit low parasitaemia for up to 60 days (Alves et al. 2002). Because of the absence of symptoms, these infected individuals do not seek health care at malaria reference centres. Furthermore, active detection of asymptomatic malaria cases is hampered by the low sensitivity of microscopy-based detection techniques in identifying very low parasite burdens (Andrade et al. 2010b). Moreover, despite low concentrations of circulating parasites, individuals with asymptomatic malaria infections can transmit Plasmodium to uninfected vectors (Alves et al. 2005). This phenomenon suggests that individuals with asymptomatic Plasmodium infections may serve as an important parasite reservoir in endemic areas.

Major factors associated with asymptomatic malaria are related to the magnitude of parasite and vector exposure (Bejon et al. 2009). Indeed, it is well established that the occurrence of asymptomatic malaria is associated with increased age (Baird et al. 1991), time of residence in the endemic area and number of previous malaria episodes (Rogier \& Trape 1995). After many years of repeated infections, the host develops clinical immunity against Plasmodium. In these cases, the onset of symptoms is prevented by limiting parasite burden and controlling inflammation (Fig. 2). Intriguingly, such asymptomatic carriers have developed just enough immunity to protect them from malarial illness, but not from malarial infection. Thus, the search for biomarkers of clinical immunity must explore tools to estimate

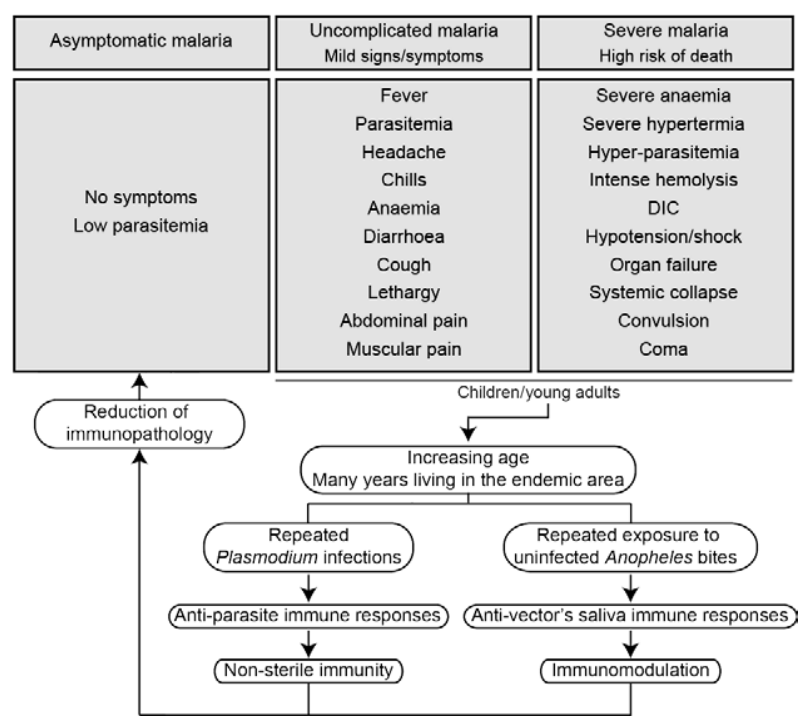

Fig. 2: clinical presentations of malaria. The boxes show common signs and symptoms of the clinical malaria spectrum. In general, children, young adults and pregnant women are the groups that are the most susceptible to mild or severe forms of malaria. With increasing age and time residing in endemic areas, individuals are repeatedly exposed to bites from uninfected vectors and also to various Plasmodium infections. Consequently, some individuals develop immune responses against both the parasite and vectors, which leads to the relative control of parasite biomass and the modulation of pathological host responses; this is commonly observed in asymptomatic malaria cases. DIC: disseminated intravascular coagulation.

both parasite/vector exposure and the host's own protective responses. Important general concepts related to biomarkers are presented in Fig. 3.

The hallmark symptom of malaria is fever, which can be followed by a wide range of other symptoms including headache, chills, diarrhoea, lethargy, coughing fits and abdominal or muscular pain (Greenwood et al. 2005). Further, more severe manifestations of malaria also vary and include anaemia, hypoglycaemia, hypotension, intense haemolysis, metabolic acidosis, spontaneous bleeding, hepatitis, acute kidney failure, respiratory distress, convulsion, coma and multiple organ failure (WHO 2000). Notably, while the parameters defining severe malaria are standardised with regard to P. falciparum infections, there are as yet no consensus criteria measuring severity of vivax malaria infections. One simple approach that has been explored is based on outcomes of clinical and laboratory tests, which are used to predict overall mortality and specific complications (Mishra et al. 2007, Winkler et al. 2008). Unlike in cases of asymptomatic malaria, parasitological diagnosis is not a major concern in severe cases, as most patients present with high levels of parasitaemia that are easily detected by microscopy-based techniques. In these situations, the critical point is to exclude mixed Plasmodium infections and other comorbidities, such as bacterial sepsis, leptospirosis, dengue, viral hepatitis and acquired immune deficiency syndrome, that can result in similar clinical presentations. Thus, the search for highly specific mark- 


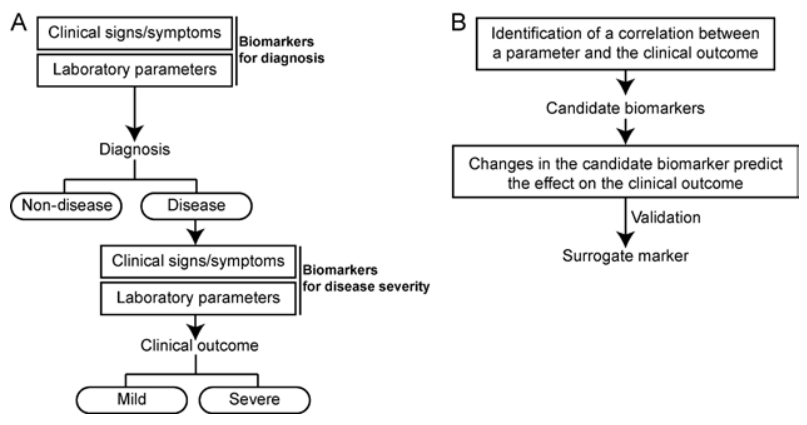

Fig. 3: key insights in biomarkers. Biomarker is anything that can be used as an indicator of a particular disease state or other physiological state. Indeed, biomarkers can be used to discriminate pathological from non-pathological conditions during diagnosis (A). Certain biomarkers are more useful for diagnosis (e.g. fever to infer Plasmodium infection), whereas others are used to predict the disease severity (e.g. coma or severe anaemia). A relevant biomarker must present very high sensitivity (few false negatives) and specificity (few false positives) to the prediction of a certain clinical endpoint (B). A surrogate marker is a laboratory measurement or a physical sign used as a substitute for a clinically meaningful endpoint that measures directly how a patient feels, functions or survives. Changes induced by a therapy on a surrogate marker are expected to reflect changes in a clinically meaningful endpoint. Thus, the primary difference between a biomarker and a surrogate marker is that a biomarker is a "candidate" surrogate marker, whereas a surrogate marker is a validated test used and taken as a measure of the effects of a specific treatment (Katz 2004).

ers should be prioritised to facilitate diagnosis. Nevertheless, less specific markers, such as those that indicate inflammatory status, are also extremely important in the light of their high sensitivity in predicting disease severity (Andrade et al. 2010d). Intense research focused on the immunopathogenesis of severe malaria will contribute to the identification of useful surrogate and specific biomarkers for cases of severe malaria.

The identification of reliable biomarkers for susceptibility to infection and for disease severity can provide important insights into the diagnosis and management of malaria. Here, we review recent research advances in the identification of malaria biomarkers, focusing on biomarkers specifically related to parasite exposure and susceptibility to disease. We also present a critical analysis of the priorities for research regarding biomarkers for severe malaria.

Biomarkers of exposure - Plasmodium is transmitted through the bites of Anopheles mosquitoes. As the insect takes a blood meal, arthropod saliva is injected into the vertebrate host. Vector saliva is essential to the Plasmodium life cycle (Choumet et al. 2007), facilitating blood feeding by inhibiting host coagulation and inflammatory responses [reviewed in Andrade et al. (2005)]. These effects may be directly linked to changes in host immune response (Depinay et al. 2006); furthermore, several of the active molecules present in vector saliva are immunogenic to vertebrate hosts, resulting in the initiation of an anti-saliva immune response. Immediate, delayed and systemic hypersensitivity reactions to vector saliva have been described [reviewed by Andrade et al. (2005)]. Vertebrate responses to arthropod salivary components have been used as epidemiological markers for vector exposure for ticks (Schwartz et al. 1991), phlebotomines (Barral et al. 2000, Gomes et al. 2002), Triatoma (Nascimento et al. 2001), Glossina (Poinsignon et al. 2008b) and Aedes mosquitoes (Remoue et al. 2007). In the case of malaria, the host immune response against vector saliva can be used as a biomarker of exposure to Anopheles.

Two points related to the detection of biomarkers in saliva must, however, be clarified. First, detection of a host immune response against saliva does not necessarily imply host protection. This is a controversial point, as both host-protective (Donovan et al. 2007) and nonprotective (Kebaier et al. 2010) findings have been reported. Currently, we utilise anti-Anopheles saliva immune responses as a marker of exposure of potential epidemiological significant. Second, the evaluation of host responses against mosquito saliva should not be confounded with diagnostic approaches that detect plasmodial products in host saliva (Wilson et al. 2008, Nwakanma et al. 2009, A-Elgayoum et al. 2010, Buppan et al. 2010, Gbotosho et al. 2010).

Antibodies against Anopheles gambiae saliva have been described in young children from a region in Senegal with seasonal malaria transmission (Remoue et al. 2006). Travellers transiently exposed to An. gambiae bites in endemic areas of Africa also develop anti-saliva antibodies (Orlandi-Pradines et al. 2007). Outside of Africa, anti-Anopheles dirus salivary protein antibodies occur predominantly in patients with acute $P$. falciparum or $P$. vivax malaria; people from non-endemic areas do not carry such antibodies (Waitayakul et al. 2006).

In the Americas, the presence of anti-Anopheles saliva antibodies has been described in malaria-endemic areas. Adult volunteers from communities in the state of Rondônia, Brazil, were tested for antibodies against Anopheles darlingi salivary gland sonicates (SGS), as this species is a prevalent malaria vector in Brazil. Individuals infected with $P$. vivax presented higher levels of anti-SGS antibodies than did non-infected individuals. This test is potentially useful as an epidemiological tool; antibody levels could discriminate between infection and non-infection with a high likelihood ratio (Andrade et al. 2009). Using a similar approach, a recent study associated the presence of anti-Anopheles albimanus saliva antibodies with mosquito bite exposure in Haiti, but did not connect these results with clinical outcomes (Londono-Renteria et al. 2010). The practical large-scale application of serological tests to detect vector salivaspecific antibodies for epidemiological purposes has been hampered by the difficulty in obtaining sufficient quantities of vector saliva and by problems in the standardisation of the reagent. Recently, the feasibility of using peptide markers to identify exposure to Anopheles bites has been demonstrated (Poinsignon et al. 2008a).

Biomarkers of susceptibility - There is now strong evidence that high frequencies of genetic disorders, predominately those involving haemoglobin and red blood cell metabolic pathways and membranes, reflect relative resistance to malaria. One of the most famous genetic disorders associated with protection against death or severe disease is the sickle cell trait, haemoglobin $\mathrm{S}(\mathrm{HbS})$. 
The gene for $\mathrm{HbS}$ is widely distributed throughout many tropical regions, including sub-Saharan Africa, the Middle East and India. The first study to propose the relationship between the $\mathrm{HbS}$ variant and falciparum malaria showed high frequencies of the sickle cell trait in non-infected children from highly endemic areas and a relative rarity of $\mathrm{HbS}$ in individuals with severe disease [reviewed in Weatherall (2008)]. Although the mechanism of protection remains unknown, it has been established that the parasitised erythrocytes from a patient with sickle cell trait are much more susceptible to sickling compared to non-parasitised cells (Luzzatto et al. 1970). Thus, the removal of sickling red cells in the spleen increases the rate of parasite clearance, reducing parasitaemia and therefore the magnitude of symptoms. In addition, sickle cell carriers had significantly higher titres of IgG antibodies against a panel of malaria antigens compared to non-carrier children (Cabrera et al. 2005). A range of other possible mechanisms, however, may protect sickle cell trait carriers from severe malaria and these should be explored in further studies.

Many other red blood cell mutations, such as haemoglobin C (Fairhurst et al. 2005) and alpha thalassaemia (Allen et al. 1997, Mockenhaupt et al. 2004, Williams et al. 2005) are associated with some degree of protection against falciparum malaria. The mechanisms of protection against malaria are commonly linked to reduced parasite replication within infected cells or the enhanced clearance of infected erythrocytes resulting from abnormal erythrocyte fragility (Pasvol et al. 1978, 1982, López et al. 2010). For other genetic disorders, the mechanism of protection is less well understood; this is the case for glucose-6-phosphate-dehydrogenase (G6PD) deficiency, the most common enzymopathy worldwide (Nkhoma et al. 2009). It is likely that this condition enhances red blood cell fragility as a result of increased susceptibility to oxidative stress (Cappadoro et al. 1998). Although it is protective against malaria, G6PD deficiency is also linked to a severe haemolytic syndrome triggered by primaquine, a primary drug used to treat $P$. vivax infections (Cappadoro et al. 1998). Beyond advancing the understanding of protective mechanisms, more effort is needed in applying this knowledge to the development of practical prophylactic or therapeutic tools.

The Duffy blood group antigen illustrates how genetic epidemiology can drive essential insights into the molecular basis of malaria. Epidemiological studies first suggested that individuals lacking the Duffy antigen/chemokine receptor (DARC) were relatively protected against vivax malaria (Miller et al. 1976). Later evidence revealed that $P$. vivax molecules bind to DARC and are important for parasite invasion (Chitnis \& Miller 1994). Recent studies have shown that $P$. vivax infections are common in Duffynegative people (Cavasini et al. 2007a, b, Ménard et al. 2010), bringing attention to the question of the real role of Duffy antigens in Plasmodium infectivity.

In addition to genetic determinants, there are a number of other interesting markers of malaria susceptibility. One such marker is the initial inflammatory response to Anopheles bites. Levels of antibodies against An. gambiae saliva were higher in young children who developed clini- cal malaria episodes than those that remained asymptomatic; these findings were interpreted to mean that the anti-saliva response is a potential marker for the risk of falciparum malaria (Remoue et al. 2006). Additionally, individuals with asymptomatic $P$. vivax parasitaemia presented higher anti-saliva antibody titres and a lower interferon-gamma (IFN $\gamma$ )/interleukin (IL)-10 ratio than symptomatic individuals; furthermore, the IFN $\gamma / \mathrm{IL}-10$ ratio was inversely correlated to anti-SGS titres in asymptomatic individuals (Andrade et al. 2009). Unfortunately, there is little data regarding cellular immune responses against salivary antigens; such responses are commonly observed in other diseases such as leishmaniasis (Gomes et al. 2002). It is important to verify whether the manipulation of a host's immune response against vector saliva can influence susceptibility to infection.

It is well established that antibodies and T cells have crucial roles in protective immunity against the different life cycle stages of Plasmodium (Good et al. 1998). Antibodies against merozoite surface molecules inhibit parasite invasion of new erythrocytes (Giha et al. 2000). Some classes of antibodies, mainly the IgG isotype, directed against antigens of $P$. falciparum erythrocytes are important in antimalarial immunity; the transfer of serum from an immune person to a non-immune is protective against infection (McGregor 1964). Humoral responses can also target sporozoites, reducing parasite invasion of hepatocytes (Hisaeda et al. 2005) or, as the case of anti-P. falciparum merozoite surface protein 1 , humoral responses can interfere with the attachment of infected erythrocytes to the endothelium (Giha et al. 2000). Furthermore, specific antibodies against glycosylphosphatidylinositol, an immunostimulatory molecule, suppress macrophage activation, thus decreasing cytokine production and inflammation (Schofield et al. 2002). Additionally, host antibodies directed against gametocytes interfere with the transmission of parasites to new vector mosquitoes. Although this type of immunity does not protect infected individuals, it may help to reduce infection at the community level.

Biomarkers of severity - Severe malaria is a highly lethal condition that requires intensive care. As a result of their immunocompromised state, children and pregnant women are the most susceptible to complications from $P$. falciparum infection. Although severe cases of vivax malaria are also associated with younger age (Andrade et al. 2010c), adults appear to be susceptible even in regions with moderate to high endemicities. Multiple factors have been implicated in the pathogenesis of severe malaria caused by either $P$. vivax or $P$. falciparum infection, including uncontrolled cytokine production (Clark et al. 2006), intense haemolysis (Yeo et al. 2009, Andrade et al. 2010a) and erythropoiesis suppression (Lamikanra et al. 2007). In addition, systemic endothelial damage and obstruction of blood flow are important contributors to lethal outcomes, mainly in $P$. falciparum infections (Schofield \& Grau 2005, Schofield 2007).

Several different biomarkers have been described as useful predictors of severe malaria and many of these were discovered based on understanding of Plasmodium 
immunopathogenesis. The majority of what is known concerning severe malaria is related to P. falciparum infections, most likely because of this parasite's large disease burden in Africa. Because P. vivax infection has been relatively neglected compared to falciparum malaria, the factors involved in its pathogenesis are less well understood; furthermore, biomarkers for vivax malaria susceptibility and disease severity are largely unknown. Many factors have been associated with severe forms of malaria and most efforts have focused on distinguishing cerebral malaria $(\mathrm{CM})$ and severe malarial anaemia from other diseases caused by uncomplicated infections. One simple factor that can influence malaria severity is parasitaemia. In P. falciparum infections, parasitaemia is directly linked to the severity of symptoms (WHO 2000). In vivax malaria, the limit of parasitaemia that can trigger pathological events is lower, so patients with relatively few circulating parasites can exhibit the inflammatory cytokine overproduction that results in fever and other complications (Karunaweera et al. 1992, Hemmer et al. 2006). In addition, as $P$. vivax preferentially infects reticulocytes, parasitaemia rarely exceeds $2 \%$ of circulating red blood cells and high parasite burdens are not a common feature of severe vivax malaria. Indeed, in two studies carried out in the Brazilian Amazon, patients with severe vivax malaria presented diverse parasite burdens (Alexandre et al. 2010, Andrade et al. 2010c). Differentiating CM from other causes of serious illness in endemic areas is complicated by the non-specific clinical presentation and the high prevalence of incidental $P$. falciparum parasitaemia (Conroy et al. 2010). Knowledge of the pathogenesis of $\mathrm{CM}$ and the identification of cytoadherence in P. falciparum and P. vivax (Carvalho et al. 2010) led us to test mediators associated with endothelial activation or damage. The angiogenic factor angiopoietin-2 is released from endothelial cells with reduced nitric oxide bioavailability in cases of CM (Lovegrove et al. 2009); it contributes to endothelial activation, sequestration of parasite biomass, impaired perfusion and poor clinical outcome (Yeo et al. 2008). Other strong predictors of CM that can be measured in plasma are intracellular adhesion molecule-1 (Conroy et al. 2010), interferon gamma-inducible protein 10 (IP-10), soluble tumour necrosis factor receptors (sTNF-R) and soluble FAS molecules. These molecules were independently associated with increased risk of CM-associated mortality (Jain et al. 2008). Many other markers, including IFN $\gamma$, IP-10, IL-8, MIP-1 $\beta$, IL-1RA, FAS-L, sTNF-R1 and sTNF-R2, could be identified in the cerebrospinal fluid of patients with lethal CM, suggesting their involvement in CM neuropathology (Yeo et al. 2008). Recently, cell-specific microparticles, which indicate cellular damage, were demonstrated to be biological markers for cerebral dysfunction in human CM (Pankoui Mfonkeu et al. 2010). Interestingly, elevated plasma concentrations of microparticles were also found in individuals with noncomplicated $P$. vivax infection in a study conducted in the Brazilian Amazon (Campos et al. 2010), suggesting that platelet-derived microparticles may play a role in the onset of acute inflammatory symptoms of vivax malaria. These results also suggest that the microparticles are a potential biomarker for severity of malaria caused by $P$. falciparum or $P$. vivax. Many of these candidate biomarkers could be combined in a multiplex immunoassay, which could be validated in broader applications.

IL-10, together with TNF- $\alpha$ and erythropoietin, has been described as a good predictor of severe anaemia (Ageely et al. 2008, Ouma et al. 2008). Recently, the IFN $\gamma /$ IL-10 ratio has been successfully used as a marker for pathological inflammatory activity in patients with varying disease severity (Andrade et al. 2010c). The most famous inflammatory marker of severe malaria is TNF- $\alpha$, which is tightly associated with fever, paroxysms, anaemia, CM (Karunaweera et al. 2003, Armah et al. 2005) and many other systemic symptoms of the infection.

It is worthy of note that as all of these markers are based on immunopathogenesis and not on the presence of the parasite itself, they have limitations in their use. After differential diagnosis, but before the onset of severe symptoms, some biomarkers can be used as predictors of complications or mortality, which could prove important in the management of potentially lethal infections. Accordingly, factors that indicate not only inflammatory status but also oxidative stress and damage to specific organs can easily be used in predictive models; they may serve as surrogate markers of disease severity. In addition, as the objective of the prediction is to influence the clinical outcome, the specificity of these markers is not critical. Indeed, non-parasite-specific markers have been shown to be powerful tools. Haemolysis, for example, is inherent to the Plasmodium life cycle during the symptomatic phase of the disease (Ekvall et al. 2001). The acute haemolysis observed in severe malaria cases results in abnormally high concentrations of free heme, which subsequently induces the production of superoxide radicals (Delmas-Beauvieux et al. 1995), cell death (Gozzelino $\&$ Soares 2011) and an imbalance between pro-inflammatory and anti-inflammatory mediators (Andrade et al. 2010a). Recently, we have shown that haemolysis related to high plasma levels of indirect bilirubin, total heme and $\mathrm{Cu} / \mathrm{Zn}$ superoxide dismutase (SOD1) is consistently associated with severe vivax malaria (Andrade et al. 2010a). Furthermore, SOD1 is a better predictor of severe vivax malaria than are plasma levels of TNF- $\alpha$ (Andrade et al. 2010d), but this biomarker cannot be used to discriminate between $P$. vivax and $P$. falciparum infections. In a recent study of a cohort of patients with different clinical presentations of vivax malaria, we described a series of promising markers of severe disease (Andrade et al. 2010c). These markers can be easily measured and can be used to generate a score that is strongly associated with unfavourable outcomes. The markers included plasma creatinine, urea, $\mathrm{C}$ reactive protein, fibrinogen, bilirubins, hepatic transaminases and heme oxygenase-1. Some of these mediators were evaluated and found to have very high discriminating power (Fig. 4). A summary of some promising biomarkers of clinical protection or disease severity is illustrated in Fig. 5.

Future perspectives - Although much published data exists regarding new biomarkers for malaria susceptibility and disease severity, few studies provide validation of their results using large samples or multi-centre ap- 


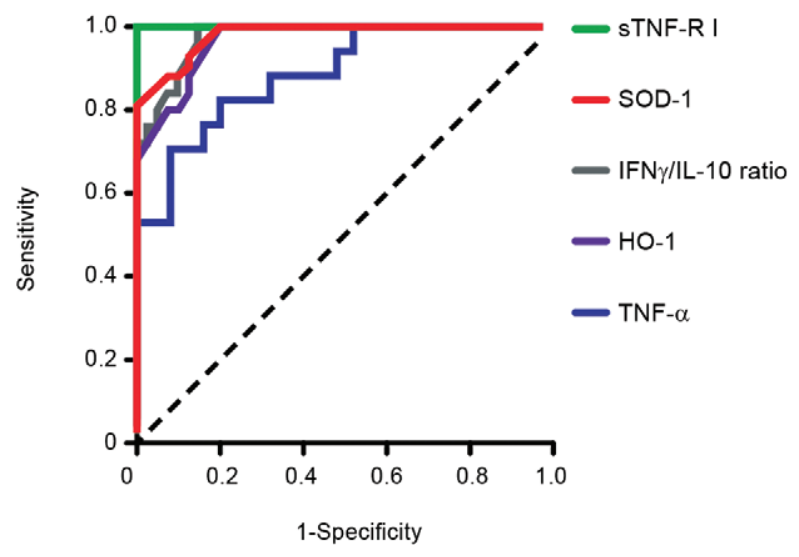

Fig. 4: assessment of the prediction performance of different candidate biomarkers for severe vivax malaria - Plasma levels of soluble tumor necrosis factor receptor I (sTNF-R I), $\mathrm{Cu} / \mathrm{Zn}$ superoxide dismutase (SOD-1), interferon-gamma (IFN $\gamma$ ), interleukin (IL)-10 (displayed as IFN $\gamma /$ IL-10 ratio), heme oxygenase 1 (HO-1) and TNF- $\alpha$ were measured in 19 patients with severe vivax malaria and from 60 individuals with mild P. vivax infection in the Brazilian Amazon during 20062007. Information about this cohort of patients can be found elsewhere (Andrade et al. 2010c). Receiver operator characteristics curves were used to compare the power of each mediator to discriminate severe malaria cases from mild infections. The area under the curve is a primary way to compare the power of each marker. Within these candidate markers, sTNF-R I presented the highest sensitivity, specificity, and likelihood ratio to predict severe cases of malaria. Larger prospective studies are necessary to validate these findings.

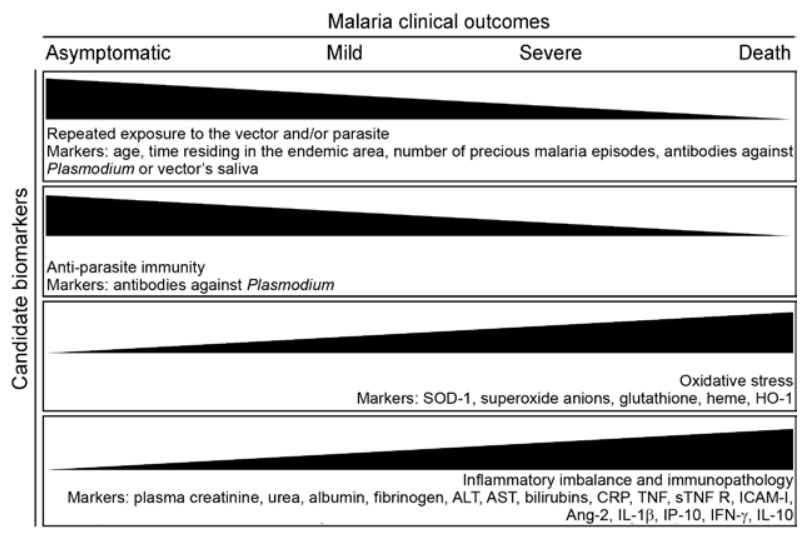

Fig. 5: potential biomarkers of susceptibility and disease severity in human malaria. The panels illustrate the association between different candidate biomarkers and clinical outcomes. Indeed, asymptomatic malaria is associated with repeated exposure to the vector and/or the parasite and with the development of non-sterile anti-parasite immunity [named "premunition," firstly reviewed in Pérignon and Druilhe (1994)]. On the opposite pole, severe and lethal malaria is directly associated with intense oxidative stress and inflammatory imbalance that results in immunopathology. Some markers are highly specific to infection, such as antibodies against Plasmodium, whereas other markers identify parameters sensitive to tissue damage and disease complications. The former are important markers for diagnosis and the later are fundamental to estimate prognosis. Despite their fundamental role in the host's protective or pathological responses, genetic markers are not listed in this figure. ALT: alanine aminotransferase; Ang-2: angiopoietin-2; AST: aspartate aminotransferase; CRP: C reactive protein; HO-1: heme oxygenase 1; ICAM-I: intracellular adhesion molecule-1; IFN $\gamma$ : interferon-gamma; IL: interleukin; IP-10: inducible protein-10 (CXCL10); SOD: superoxide dismutase; TNF: tumor necrosis factor; sTNF-R: soluble TNF receptors. proaches. Coordinated initiatives are necessary to design robust validation studies and generate standardised guidelines. One potential approach is the screening for susceptibility signatures using high-throughput analyses. Another method is the creation of tools using combinations of powerful biomarkers to quantify the degree of malaria susceptibility and severity. The use of a combination of biomarkers instead of one specific candidate could increase reliability and predictive power. Network analyses are necessary to address this demand, as they can provide an understanding of the real relationship between candidate biomarkers and pathological processes or clinical and parasitic determinants. Furthermore, we should emphasise larger epidemiological human studies that examine the vector-host-parasite relationship to reveal potential markers. Caution, however, is needed in the search for the ideal biomarker of malaria severity. Validation studies must be designed to discriminate between severe cases caused by $P$. vivax and P. falciparum. Until now, the research on falciparum malaria has been much more advanced, mostly because of the higher incidence of lethal cases. Consensus criteria to classify severe vivax malaria are now necessary; lacking such criteria, candidate biomarkers validated in studies with falciparum malaria may show weak or no correlation with vivax malaria severity and vice versa. Aside from investigating genetic determinants of the disease, the search for good predictors of susceptibility or severity must involve the generation of simple and cheap tools that can be implemented in undeveloped endemic areas.

\section{ACKNOWLEDGEMENTS}

To Dr Daniel L Barber, for critical discussions.

\section{REFERENCES}

A-Elgayoum SM, El-Rayah el-A, Giha HA 2010. Towards a noninvasive approach to malaria diagnosis: detection of parasite DNA in body secretions and surface mucosa. $J$ Mol Microbiol Biotechnol 18: 148-155.

Ageely HM, Dawoud HA, Heiba AA 2008. Anemia, interleukin-10, tumor necrosis factor alpha, and erythropoietin levels in children with acute, complicated and uncomplicated malignant malaria in Jazan, Saudi Arabia. J Egypt Soc Parasitol 38: 359-370.

Alexandre MA, Ferreira CO, Siqueira AM, Magalhães BL, Mourão MP, Lacerda MV, Alecrim MG 2010. Severe Plasmodium vivax malaria, Brazilian Amazon. Emerg Infect Dis 16: 1611-1614.

Allen SJ, O'Donnell A, Alexander ND, Alpers MP, Peto TE, Clegg JB, Weatherall DJ 1997. Alpha+-thalassemia protects children against disease caused by other infections as well as malaria. Proc Natl Acad Sci USA 94: 14736-14741.

Alves FP, Durlacher RR, Menezes MJ, Krieger H, Silva LH, Camargo EP 2002. High prevalence of asymptomatic Plasmodium vivax and Plasmodium falciparum infections in native Amazonian populations. Am J Trop Med Hyg 66: 641-648.

Alves FP, Gil LH, Marrelli MT, Ribolla PE, Camargo EP, Da Silva LH 2005. Asymptomatic carriers of Plasmodium spp as infection source for malaria vector mosquitoes in the Brazilian Amazon. J Med Entomol 42: 777-779.

Andrade BB, Araújo-Santos T, Luz NF, Khouri R, Bozza MT, Camargo LM, Barral A, Borges VM, Barral-Netto M 2010a. Heme impairs prostaglandin E2 and TGF-beta production by human mononuclear cells via $\mathrm{Cu} / \mathrm{Zn}$ superoxide dismutase: insight into the pathogenesis of severe malaria. J Immunol 185: 1196-1204. 
Andrade BB, Reis-Filho A, Barros AM, Souza-Neto SM, Nogueira LL, Fukutani KF, Camargo EP, Camargo LM, Barral A, Duarte A, Barral-Netto M 2010b. Towards a precise test for malaria diagnosis in the Brazilian Amazon: comparison among field microscopy, a rapid diagnostic test, nested PCR, and a computational expert system based on artificial neural networks. Malar J 9: 117.

Andrade BB, Reis-Filho A, Souza-Neto SM, Clarêncio J, Camargo LM, Barral A, Barral-Netto M 2010c. Severe Plasmodium vivax malaria exhibits marked inflammatory imbalance. Malar J 9: 13.

Andrade BB, Reis-Filho A, Souza-Neto SM, Raffaele-Netto I, Camargo LM, Barral A, Barral-Netto M 2010d. Plasma superoxide dismutase-1 as a surrogate marker of vivax malaria severity. PLoS Negl Trop Dis 4: e650.

Andrade BB, Rocha BC, Reis-Filho A, Camargo LM, Tadei WP, Moreira LA, Barral A, Barral-Netto M 2009. Anti-Anopheles darlingi saliva antibodies as marker of Plasmodium vivax infection and clinical immunity in the Brazilian Amazon. Malar J 8: 121.

Andrade BB, Teixeira CR, Barral A, Barral-Netto M 2005. Haematophagous arthropod saliva and host defense system: a tale of tear and blood. An Acad Bras Cienc 77: 665-693.

Anstey NM, Russell B, Yeo TW, Price RN 2009. The pathophysiology of vivax malaria. Trends Parasitol 25: 220-227.

Armah H, Wired EK, Dodoo AK, Adjei AA, Tettey Y, Gyasi R 2005. Cytokines and adhesion molecules expression in the brain in human cerebral malaria. Int J Environ Res Public Health 2: 123-131.

Baird JK, Jones TR, Danudirgo EW, Annis BA, Bangs MJ, Basri H, Purnomo, Masbar S 1991. Age-dependent acquired protection against Plasmodium falciparum in people having two years exposure to hyperendemic malaria. Am J Trop Med Hyg 45: 65-76.

Baliraine FN, Afrane YA, Amenya DA, Bonizzoni M, Menge DM, Zhou G, Zhong D, Vardo-Zalik AM, Githeko AK, Yan G 2009. High prevalence of asymptomatic Plasmodium falciparum infections in a highland area of western Kenya: a cohort study. J Infect Dis 200: 66-74.

Barral A, Honda E, Caldas A, Costa J, Vinhas V, Rowton ED, Valenzuela JG, Charlab R, Barral-Netto M, Ribeiro JM 2000. Human immune response to sand fly salivary gland antigens: a useful epidemiological marker? Am J Trop Med Hyg 62: 740-745.

Bejon P, Warimwe G, Mackintosh CL, Mackinnon MJ, Kinyanjui SM, Musyoki JN, Bull PC, Marsh K 2009. Analysis of immunity to febrile malaria in children that distinguishes immunity from lack of exposure. Infect Immun 77: 1917-1923.

Buppan P, Putaporntip C, Pattanawong U, Seethamchai S, Jongwutiwes S 2010. Comparative detection of Plasmodium vivax and Plasmodium falciparum DNA in saliva and urine samples from symptomatic malaria patients in a low endemic area. Malar J 9: 72

Cabrera G, Cot M, Migot-Nabias F, Kremsner PG, Deloron P, Luty AJ 2005. The sickle cell trait is associated with enhanced immunoglobulin $\mathrm{G}$ antibody responses to Plasmodium falciparum variant surface antigens. $J$ Infect Dis 191: 1631-1638.

Campos FM, Franklin BS, Teixeira-Carvalho A, Filho AL, de Paula SC, Fontes CJ, Brito CF, Carvalho LH 2010. Augmented plasma microparticles during acute Plasmodium vivax infection. Malar J 9: 327.

Cappadoro M, Giribaldi G, O'Brien E, Turrini F, Mannu F, Ulliers D, Simula G, Luzzatto L, Arese P 1998. Early phagocytosis of glucose-6-phosphate dehydrogenase (G6PD)-deficient erythrocytes parasitized by Plasmodium falciparum may explain malaria protection in G6PD deficiency. Blood 92: 2527-2534.

Carvalho BO, Lopes SC, Nogueira PA, Orlandi PP, Bargieri DY, Blanco YC, Mamoni R, Leite JA, Rodrigues MM, Soares IS, Oliveira TR, Wunderlich G, Lacerda MV, del Portillo HA, Araújo
MO, Russell B, Suwanarusk R, Snounou G, Rénia L, Costa FT 2010. On the cytoadhesion of Plasmodium vivax-infected erythrocytes. J Infect Dis 202: 638-647.

Cavasini CE, de Mattos LC, Couto AA, Couto VS, Gollino Y, Moretti LJ, Bonini-Domingos CR, Rossit AR, Castilho L, Machado RL 2007a. Duffy blood group gene polymorphisms among malaria vivax patients in four areas of the Brazilian Amazon region. Malar J 6: 167.

Cavasini CE, Mattos LC, Couto AA, Bonini-Domingos CR, Valencia SH, Neiras WC, Alves RT, Rossit AR, Castilho L, Machado RL 2007b. Plasmodium vivax infection among Duffy antigen-negative individuals from the Brazilian Amazon region: an exception? Trans R Soc Trop Med Hyg 101: 1042-1044.

Chitnis CE, Miller LH 1994. Identification of the erythrocyte binding domains of Plasmodium vivax and Plasmodium knowlesi proteins involved in erythrocyte invasion. J Exp Med 180: 497-506.

Choumet V, Carmi-Leroy A, Laurent C, Lenormand P, Rousselle JC, Namane A, Roth C, Brey PT 2007. The salivary glands and saliva of Anopheles gambiae as an essential step in the Plasmodium life cycle: a global proteomic study. Proteomics 7: 3384-3394.

Clark IA, Budd AC, Alleva LM, Cowden WB 2006. Human malarial disease: a consequence of inflammatory cytokine release. Malar J 5: 85.

Clark IA, Cowden WB 1999. Why is the pathology of falciparum worse than that of vivax malaria? Parasitol Today 15: 458-461.

Conroy AL, Phiri H, Hawkes M, Glover S, Mallewa M, Seydel KB, Taylor TE, Molyneux ME, Kain KC 2010. Endothelium-based biomarkers are associated with cerebral malaria in Malawian children: a retrospective case-control study. PLOS ONE 5: e15291.

Cox-Singh J, Hiu J, Lucas SB, Divis PC, Zulkarnaen M, Chandran P, Wong KT, Adem P, Zaki SR, Singh B, Krishna S 2010. Severe malaria - a case of fatal Plasmodium knowlesi infection with post-mortem findings: a case report. Malar J 9: 10.

Cucunubá ZM, Guerra AP, Rahirant SJ, Rivera JA, Cortés LJ, Nicholls RS 2008. Asymptomatic Plasmodium spp infection in Tierralta, Colombia. Mem Inst Oswaldo Cruz 103: 668-673.

Delmas-Beauvieux MC, Peuchant E, Dumon MF, Receveur MC, Le Bras M, Clerc M 1995. Relationship between red blood cell antioxidant enzymatic system status and lipoperoxidation during the acute phase of malaria. Clin Biochem 28: 163-169.

Depinay N, Hacini F, Beghdadi W, Peronet R, Mécheri S 2006. Mast cell-dependent down-regulation of antigen-specific immune responses by mosquito bites. J Immunol 176: 4141-4146.

Donovan MJ, Messmore AS, Scrafford DA, Sacks DL, Kamhawi S, McDowell MA 2007. Uninfected mosquito bites confer protection against infection with malaria parasites. Infect Immun 75: 2523-2530.

Ekvall H, Arese P, Turrini F, Ayi K, Mannu F, Premji Z, Bjorkman A 2001. Acute haemolysis in childhood falciparum malaria. Trans $R$ Soc Trop Med Hyg 95: 611-617.

Fairhurst RM, Baruch DI, Brittain NJ, Ostera GR, Wallach JS, Hoang HL, Hayton K, Guindo A, Makobongo MO, Schwartz OM, Tounkara A, Doumbo OK, Diallo DA, Fujioka H, Ho M, Wellems TE 2005. Abnormal display of PfEMP-1 on erythrocytes carrying haemoglobin C may protect against malaria. Nature 435: 1117-1121.

Gbotosho GO, Happi CT, Folarin O, Keyamo O, Sowunmi A, Oduola AM 2010. Rapid detection of lactate dehydrogenase and genotyping of Plasmodium falciparum in saliva of children with acute uncomplicated malaria. Am J Trop Med Hyg 83: 496-501.

Giha HA, Staalsoe T, Dodoo D, Roper C, Satti GM, Arnot DE, Hviid L, Theander TG 2000. Antibodies to variable Plasmodium falciparum-infected erythrocyte surface antigens are associated with protection from novel malaria infections. Immunol Lett 71: 117-126. 
Gomes RB, Brodskyn C, de Oliveira CI, Costa J, Miranda JC, Caldas A, Valenzuela JG, Barral-Netto M, Barral A 2002. Seroconversion against Lutzomyia longipalpis saliva concurrent with the development of anti-Leishmania chagasi delayed-type hypersensitivity. J Infect Dis 186: 1530-1534.

Good MF, Kaslow DC, Miller LH 1998. Pathways and strategies for developing a malaria blood-stage vaccine. Annu Rev Immunol 16: 57-87.

Gozzelino R, Soares MP 2011. Heme sensitization to TNF-mediated programmed cell death. Adv Exp Med Biol 691: 211-219.

Greenwood BM, Bojang K, Whitty CJ, Targett GA 2005. Malaria. Lancet 365: 1487-1498.

Guerra CA, Gikandi PW, Tatem AJ, Noor AM, Smith DL, Hay SI, Snow RW 2008. The limits and intensity of Plasmodium falciparum transmission: implications for malaria control and elimination worldwide. PLoS Med 5: e38.

Guerra CA, Howes RE, Patil AP, Gething PW, Van Boeckel TP, Temperley WH, Kabaria CW, Tatem AJ, Manh BH, Elyazar IR, Baird JK, Snow RW, Hay SI 2010. The international limits and population at risk of Plasmodium vivax transmission in 2010. PLoS Negl Trop Dis 4: e774.

Hay SI, Guerra CA, Gething PW, Patil AP, Tatem AJ, Noor AM, Kabaria CW, Manh BH, Elyazar IR, Brooker S, Smith DL, Moyeed RA, Snow RW 2009. A world malaria map: Plasmodium falciparum endemicity in 2007. PLoS Med 6: e1000048.

Hemmer CJ, Holst FG, Kern P, Chiwakata CB, Dietrich M, Reisinger EC 2006. Stronger host response per parasitized erythrocyte in Plasmodium vivax or ovale than in Plasmodium falciparum malaria. Trop Med Int Health 11: 817-823.

Hisaeda H, Yasutomo K, Himeno K 2005. Malaria: immune evasion by parasites. Int J Biochem Cell Biol 37: 700-706.

Jain V, Armah HB, Tongren JE, Ned RM, Wilson NO, Crawford S, Joel PK, Singh MP, Nagpal AC, Dash AP, Udhayakumar V, Singh N, Stiles JK 2008. Plasma IP-10, apoptotic and angiogenic factors associated with fatal cerebral malaria in India. Malar J 7: 83.

Karunaweera ND, Grau GE, Gamage P, Carter R, Mendis KN 1992. Dynamics of fever and serum levels of tumor necrosis factor are closely associated during clinical paroxysms in Plasmodium vivax malaria. Proc Natl Acad Sci USA 89: 3200-3203.

Karunaweera ND, Wijesekera SK, Wanasekera D, Mendis KN, Carter R 2003. The paroxysm of Plasmodium vivax malaria. Trends Parasitol 19: 188-193.

Katz R 2004. Biomarkers and surrogate markers: an FDA perspective. NeuroRx 1: 189-195.

Kebaier C, Voza T, Vanderberg J 2010. Neither mosquito saliva nor immunity to saliva has a detectable effect on the infectivity of Plasmodium sporozoites injected into mice. Infect Immun 78: 545-551.

Lamikanra AA, Brown D, Potocnik A, Casals-Pascual C, Langhorne J, Roberts DJ 2007. Malarial anemia: of mice and men. Blood 110: 18-28.

Londono-Renteria BL, Eisele TP, Keating J, James MA, Wesson DM 2010. Antibody response against Anopheles albimanus (Diptera: Culicidae) salivary protein as a measure of mosquito bite exposure in Haiti. J Med Entomol 47: 1156-1163.

López C, Saravia C, Gomez A, Hoebeke J, Patarroyo MA 2010. Mechanisms of genetically-based resistance to malaria. Gene 467: 1-12.

Lovegrove FE, Tangpukdee N, Opoka RO, Lafferty EI, Rajwans N, Hawkes M, Krudsood S, Looareesuwan S, John CC, Liles WC, Kain KC 2009. Serum angiopoietin-1 and -2 levels discriminate cerebral malaria from uncomplicated malaria and predict clinical outcome in African children. PLoS ONE 4: e4912.
Luzzatto L, Nwachuku-Jarrett ES, Reddy S 1970. Increased sickling of parasitised erythrocytes as mechanism of resistance against malaria in the sickle-cell trait. Lancet 1: 319-321.

Marangi M, Di Tullio R, Mens PF, Martinelli D, Fazio V, Angarano G, Schallig HD, Giangaspero A, Scotto G 2009. Prevalence of Plasmodium spp in malaria asymptomatic African migrants assessed by nucleic acid sequence based amplification. Malar J 8: 12 .

McGregor IA 1964. The passive transfer of human malarial immunity. Am J Trop Med Hyg 13 (Suppl.): 237-239.

Ménard D, Barnadas C, Bouchier C, Henry-Halldin C, Gray LR, Ratsimbasoa A, Thonier V, Carod JF, Domarle O, Colin Y, Bertrand O, Picot J, King CL, Grimberg BT, Mercereau-Puijalon O, Zimmerman PA 2010. Plasmodium vivax clinical malaria is commonly observed in Duffy-negative Malagasy people. Proc Natl Acad Sci USA 107: 5967-5971.

Miller LH, Mason SJ, Clyde DF, McGinniss MH 1976. The resistance factor to Plasmodium vivax in blacks. The Duffy-blood-group genotype, FyFy. N Engl J Med 295: 302-304.

Mishra SK, Panigrahi P, Mishra R, Mohanty S 2007. Prediction of outcome in adults with severe falciparum malaria: a new scoring system. Malar J 6: 24.

Mockenhaupt FP, Ehrhardt S, Gellert S, Otchwemah RN, Dietz E, Anemana SD, Bienzle 2004. Alpha(+)-thalassemia protects African children from severe malaria. Blood 104: 2003-2006.

Nascimento RJ, Santana JM, Lozzi SP, Araújo CN, Teixeira AR 2001. Human IgG1 and IgG4: the main antibodies against Triatoma infestans (Hemiptera: Reduviidae) salivary gland proteins. $\mathrm{Am}$ J Trop Med Hyg 65: 219-226.

Nkhoma ET, Poole C, Vannappagari V, Hall SA, Beutler E 2009. The global prevalence of glucose-6-phosphate dehydrogenase deficiency: a systematic review and meta-analysis. Blood Cells $\mathrm{Mol}$ Dis 42: 267-278.

Nwakanma DC, Gomez-Escobar N, Walther M, Crozier S, Dubovsky F, Malkin E, Locke E, Conway DJ 2009. Quantitative detection of Plasmodium falciparum DNA in saliva, blood and urine. $J$ Infect Dis 199: 1567-1574.

Oliveira-Ferreira J, Lacerda MV, Brasil P, Ladislau JL, Tauil PL, DanielRibeiro CT 2010. Malaria in Brazil: an overview. Malar J 9: 115.

Orlandi-Pradines E, Almeras L, Denis de Senneville L, Barbe S, Remoué F, Villard C, Cornelie S, Penhoat K, Pascual A, Bourgouin C, Fontenille D, Bonnet J, Corre-Catelin N, Reiter P, Pagés F, Laffite D, Boulanger D, Simondon F, Pradines B, Fusaï T, Rogier C 2007. Antibody response against saliva antigens of Anopheles gambiae and Aedes aegypti in travellers in tropical Africa. Microbes Infect 9: 1454-1462.

Ouma C, Davenport GC, Were T, Otieno MF, Hittner JB, Vulule JM, Martinson J, Ong'echa JM, Ferrell RE, Perkins DJ 2008. Haplotypes of IL-10 promoter variants are associated with susceptibility to severe malarial anemia and functional changes in IL-10 production. Hum Genet 124: 515-524.

Pankoui Mfonkeu JB, Gouado I, Fotso Kuaté H, Zambou O, Amvam Zollo PH, Grau GE, Combes V 2010. Elevated cell-specific microparticles are a biological marker for cerebral dysfunctions in human severe malaria. PLOS ONE 5: e13415.

Pasvol G, Wainscoat JS, Weatherall DJ 1982. Erythrocytes deficiency in glycophorin resist invasion by the malarial parasite Plasmodium falciparum. Nature 297: 64-66.

Pasvol G, Weatherall DJ, Wilson RJ 1978. Cellular mechanism for the protective effect of haemoglobin $\mathrm{S}$ against $P$. falciparum malaria. Nature 274: 701-703. 
Pérignon JL, Druilhe P 1994. Immune mechanisms underlying the premunition against Plasmodium falciparum malaria. Mem Inst Oswaldo Cruz 89 (Suppl. II): 51-53.

Poinsignon A, Cornelie S, Mestres-Simon M, Lanfrancotti A, Rossignol M, Boulanger D, Cisse B, Sokhna C, Arcà B, Simondon F, Remoue F 2008a. Novel peptide marker corresponding to salivary protein gSG6 potentially identifies exposure to Anopheles bites. PLOS ONE 3: e2472.

Poinsignon A, Remoue F, Rossignol M, Cornelie S, Courtin D, Grébaut P, Garcia A, Simondon F 2008b. Human IgG antibody response to Glossina saliva: an epidemiologic marker of exposure to Glossina bites. Am J Trop Med Hyg 78: 750-753.

Remoue F, Alix E, Cornelie S, Sokhna C, Cisse B, Doucoure S, Mouchet F, Boulanger D, Simondon F 2007. IgE and IgG4 antibody responses to Aedes saliva in African children. Acta Trop 104: 108-115.

Remoue F, Cisse B, Ba F, Sokhna C, Herve JP, Boulanger D, Simondon F 2006. Evaluation of the antibody response to Anopheles salivary antigens as a potential marker of risk of malaria. Trans $R$ Soc Trop Med Hyg 100: 363-370.

Rogier C, Trape JF 1995. Study of premunition development in holo- and meso-endemic malaria areas in Dielmo and Ndiop (Senegal): preliminary results, 1990-1994. Med Trop (Mars) 55 (Suppl. 4): 71-76.

Schofield L 2007. Intravascular infiltrates and organ-specific inflammation in malaria pathogenesis. Immunol Cell Biol 85: 130-137.

Schofield L, Grau GE 2005. Immunological processes in malaria pathogenesis. Nat Rev Immunol 5: 722-735.

Schofield L, Hewitt MC, Evans K, Siomos MA, Seeberger PH 2002. Synthetic GPI as a candidate anti-toxic vaccine in a model of malaria. Nature 418: 785-789.

Schwartz BS, Ford DP, Childs JE, Rothman N, Thomas RJ 1991. Antitick saliva antibody: a biologic marker of tick exposure that is a risk factor for Lyme disease seropositivity. Am J Epidemiol 134: 86-95.
Steenkeste N, Rogers WO, Okell L, Jeanne I, Incardona S, Duval L, Chy S, Hewitt S, Chou M, Socheat D, Babin FX, Ariey F, Rogier C 2010. Sub-microscopic malaria cases and mixed malaria infection in a remote area of high malaria endemicity in Rattanakiri province, Cambodia: implication for malaria elimination. Malar J 9: 108.

Waitayakul A, Somsri S, Sattabongkot J, Looareesuwan S, Cui L, Udomsangpetch R 2006. Natural human humoral response to salivary gland proteins of Anopheles mosquitoes in Thailand. Acta Trop 98: 66-73.

Weatherall DJ 2008. Genetic variation and susceptibility to infection: the red cell and malaria. Br J Haematol 141: 276-286.

WHO - World Health Organization 2000. Severe falciparum malaria. Trans R Soc Trop Med Hyg 94 (Suppl. 1): 1-90.

Williams TN, Mwangi TW, Wambua S, Peto TE, Weatherall DJ, Gupta S, Recker M, Penman BS, Uyoga S, Macharia A, Mwacharo JK, Snow RW, Marsh K 2005. Negative epistasis between the malaria-protective effects of alpha+-thalassemia and the sickle cell trait. Nat Genet 37: 1253-1257.

Wilson NO, Adjei AA, Anderson W, Baidoo S, Stiles JK 2008. Detection of Plasmodium falciparum histidine-rich protein II in saliva of malaria patients. Am J Trop Med Hyg 78: 733-735.

Winkler AS, Salmhofer G, Helbok R, Kalokola F, Matuja W, Schmutzhard E 2008. In-hospital risk estimation in children with malaria - early predictors of morbidity and mortality. J Trop Pediatr 54: 184-191.

Yeo TW, Lampah DA, Gitawati R, Tjitra E, Kenangalem E, Piera K, Price RN, Duffull SB, Celermajer DS, Anstey NM 2008. Angiopoietin-2 is associated with decreased endothelial nitric oxide and poor clinical outcome in severe falciparum malaria. Proc Natl Acad Sci USA 105: 17097-17102.

Yeo TW, Lampah DA, Tjitra E, Gitawati R, Kenangalem E, Piera K, Granger DL, Lopansri BK, Weinberg JB, Price RN, Duffull SB, Celermajer DS, Anstey NM 2009. Relationship of cell-free hemoglobin to impaired endothelial nitric oxide bioavailability and perfusion in severe falciparum malaria. J Infect Dis 200: 1522-1529. 